This item was submitted to Loughborough's Research Repository by the author.

Items in Figshare are protected by copyright, with all rights reserved, unless otherwise indicated.

\title{
Membrane emulsification: Formation of water in oil emulsions using a hydrophilic membrane
}

PLEASE CITE THE PUBLISHED VERSION

http://dx.doi.org/10.1016/j.colsurfa.2017.04.077

PUBLISHER

(C) Elsevier

VERSION

AM (Accepted Manuscript)

\section{PUBLISHER STATEMENT}

This work is made available according to the conditions of the Creative Commons Attribution-NonCommercialNoDerivatives 4.0 International (CC BY-NC-ND 4.0) licence. Full details of this licence are available at: https://creativecommons.org/licenses/by-nc-nd/4.0/

\section{LICENCE}

CC BY-NC-ND 4.0

\section{REPOSITORY RECORD}

Silva, Pedro T. Santos, Victor Starov, and R.G. Holdich. 2017. "Membrane Emulsification: Formation of Water in Oil Emulsions Using a Hydrophilic Membrane". figshare. https://hdl.handle.net/2134/25764. 


\title{
Membrane emulsification: formation of water in oil emulsions using a hydrophilic membrane
}

Pedro S. Silva ${ }^{1}$, V. Starov ${ }^{1}$ and Richard G. Holdich ${ }^{1}$

${ }^{1}$ Department of Chem. Eng., Loughborough University, Leicestershire, LE11 3TU, U.K.

\begin{abstract}
It is shown that formation of water based droplets in an immiscible (i.e. oil) continuous phase can be achieved using a hydrophilic porous metal membrane without prior hydrophobic treatment of the membrane surface. This avoids the need for "health and safety approval" of typical hydrophobic treatments for the membrane, which often use chemicals incompatible with pharma or food applications. To investigate this, wetting experiments were carried out: sessile droplets were used to determine static contact angles and a rotating drum system was used to determine contact angles under dynamic conditions. In the latter case the three-phase contact line was observed between the rotating drum, water and the continuous phase used in the emulsification process; a surfactant was present in the continuous phase which, in this process, has a double function: to assist the wetting of the membrane by the continuous phase, and not the disperse phase, and to stabilize the droplets formed at the surface of the porous membrane during membrane emulsification.
\end{abstract}

\section{Keywords}

Membrane surface, hydrophilic, water in oil emulsion, polyvinyl alcohol (PVA), droplets and contact angle 


\section{Introduction}

Currently several industries rely on conventional emulsification processes using high shear rotor-stator devices and high-pressure valve homogenizers, which are not suitable when dealing with shear sensitive substances and when a controlled droplet size is required. Therefore, other emulsification techniques are often explored. Regarding low shear handling and uniform droplet size there are two systems that stand out: microfluidic devices and membrane emulsification. They both offer control over the droplet formation and operate under mild shear stress conditions. In both cases formulation and process parameters are key factors i.e., combination of parameters such as (dynamic) interfacial tension, type of surfactant, wetting characteristics of material used and viscosity of both liquids can be very important. Therefore, an erroneous choice of these parameters might make the difference between highly uniform, or very polydisperse, drop size. Comparing the two techniques they can be characterised as (i) the higher uniformity drops that microfluidics can produce and (ii) higher throughputs that membrane emulsification can achieve. Therefore, if the process to be optimised requires high throughputs then membrane emulsification is the best choice. Previously in [1] a novel membrane emulsification device was presented which operates continuously. In [1] a throughput of $1 \mathrm{~L} \mathrm{~h}^{-1}$ was tested using a $5 \mu \mathrm{m}$ pore size membrane with an interpore distance of $200 \mu \mathrm{m}$. Droplets generated at some conditions were below $50 \mu \mathrm{m}$ which suggests decreasing the interpore distance by at least three times will still avoid the contact of drops during their growth and detachment. In addition, certain applications could require the use of a bigger pore size, which combined with smaller interpore distance, gives the possibility to increase substantially the porosity of the membrane allowing much higher throughput. Thus, membrane emulsification is a technique to consider for industrial process development especially when "made to measure" drop size, low shear application and reasonable throughputs are required. However, other challenges might need to be overcome 
to implement this technique at an industrial scale, such as chemical compatibility and use of safe approved materials. Over the years users of membrane emulsification tend to use a hydrophilic porous membrane for production of oil in water $(\mathrm{o} / \mathrm{w})$ emulsions, or a hydrophobic porous membrane for production of water in oil (w/o) emulsions [2]. The most common materials used to manufacture these porous membranes have a hydrophilic nature such as metals (stainless steel $[1,3,4]$ and nickel [5-8]), Shirasu porous glass [9, 10] or ceramic (e.g. alumina oxide) [11-13]. Therefore, hydrophobic treatment of these hydrophilic membranes, or coating of their surfaces, is used when the aim is production of a w/o emulsion. Frequently, these treatments/coatings applied have problems with longevity and stability which are crucial at an industrial scale. The materials used for surface modification are subject to regulatory approval when the production of formulations for food or medical grade products are required, and this possibly becomes an obstacle to adoption of membrane emulsification. In this paper, the use of (clean) metal hydrophilic porous membranes without any extra surface modification in order to produce uniform w/o emulsions, contrary to the usually adopted procedure is explored. A solution of $13.5 \%$ wt polyvinyl alcohol (PVA) as disperse phase and kerosene as the continuous phase with the presence of surfactant: Span ${ }^{\circledR}$ 80 was used as a model system. This system was chosen because it is appropriate as an example of a possible formulation used at industrial scale for productions of uniform PVA beads, or encapsulation, via the entrapment method, of a desired ingredient.

Earlier studies [1, 5, 14] have showed a good agreement between equation 1 and drop size obtained for low injection rates using membrane emulsification. That modelling is the result of a force balance between drag force and capillary force assuming complete wetting of the continuous phase $\left(\Theta=0^{\circ}\right)$ of the pores by the continuous phase. 


$$
x=\frac{\sqrt{18 \tau^{2} r_{p}{ }^{2}+2 \sqrt{81 r_{p}{ }^{4} \tau^{4}+4 \gamma^{2} r_{p}{ }^{2} \tau^{2}}}}{3 \tau}
$$

where $r_{p}$ is the pore radius, $\tau$ is the shear stress applied, $\gamma$ is the interfacial tension and $x$ is the droplet diameter. It can be expected that the contact angle will play a considerable role in the droplet formation mechanism and consequently on the resultant droplet size (Figure 1). Therefore, in the case of partial wetting of the continuous phase $\left(0^{\circ}>\theta>90^{\circ}\right)$ resultant equation is as follows:

$$
x=\frac{\sqrt{18 \tau^{2} r_{p}{ }^{2}+2 \sqrt{81 r_{p}{ }^{4} \tau^{4}+4 \gamma^{2} r_{p}{ }^{2} \tau^{2} \cos ^{2}(\boldsymbol{\theta})}}}{3 \tau},
$$

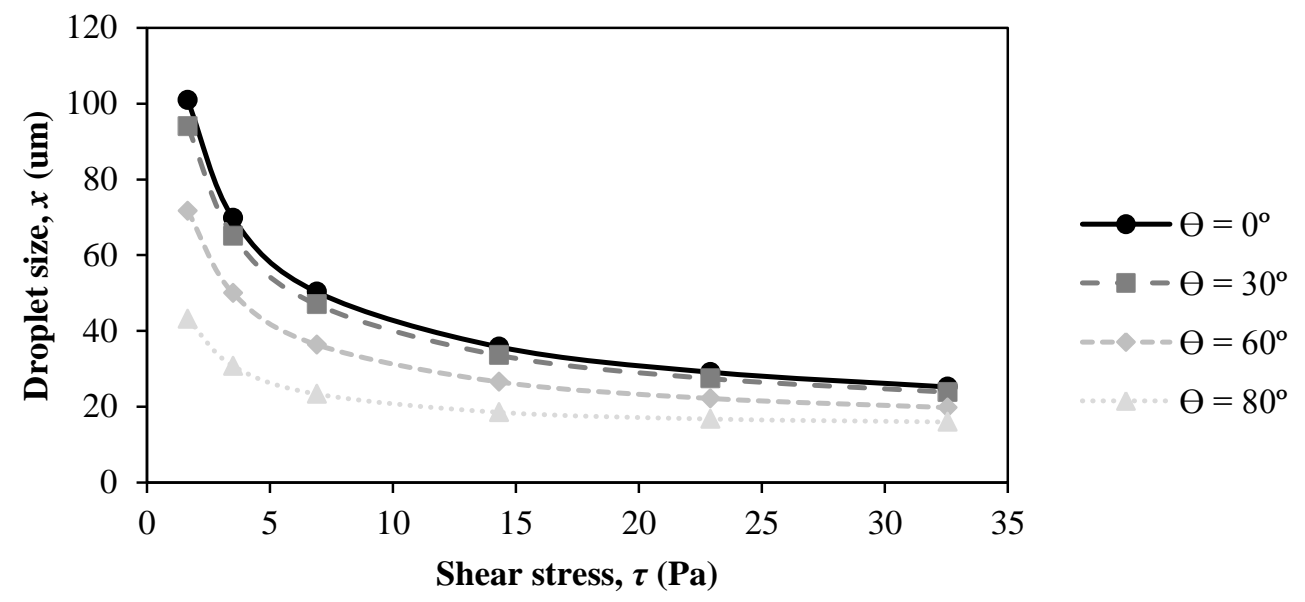

Figure 1 Influence of the contact angle on the final drop size.

Nonetheless, the force balance model (eq. 1 and 2) doesn't take into account the influence of the flux of the injecting material through the membrane. Earlier many investigations empirically found that higher flux leads to bigger droplet sizes in the dripping regime [1, 4, $5,15,16]$. Transition from dripping to jetting regime occurs above a certain critical capillary number, which is independent of the contact angle [2], but still depends on the formulation 
used. Experimental observation of the influence of contact angle of drops in a membrane emulsification device is not very straightforward and therefore different approaches were adopted below.

"Wetting and interface interaction” knowledge was acquired for the system, which includes two liquid phases and a solid phase prior to emulsification experiments. Liquid-surface interactions often have been underestimated and considered insufficiently compared with other physical parameter of membranes, such as, pore size distribution and pore distance. The latter parameters become irrelevant when the surface chemistry is not adequately adjusted [17]. The importance of interactions between liquid-liquid and liquid-solid can be seen in other two phase systems processes such as emulsion separation using membranes [2].

Wetting properties of a system: two immiscible liquids and a solid surface, is the contact angle. The sessile drop method is frequently used for measuring static contact angles between three different phases, i.e. solid, liquid and vapour, but the principle is equally applicable to the interface of two liquids and a solid. Drops deposited on the surface were surrounded by an immiscible liquid with, or without, the presence of surfactant $[18,19]$. The presence of amphiphilic molecules in a solution affects the wettability of a surface in contact with the solution [20].

G. K. Auernhammer and his co-workers are currently using a rotating drum setup for studying velocity-dependent wetting/dewetting processes of complex (surfactant) solutions between a solid-gas-liquid interface [21-24]. Below a similar setup is adopted, however, the vapour phase is replaced by an organic phase to allow the investigation of wetting properties between two liquids and a solid phase. Two immiscible liquids were in contact with the surface (316 Stainless steel) of the drum which is the surface that was treated similarly to the porous membranes used in membrane emulsification experiments. In Figure 2, a schematic diagram of the side view of the drum is presented. Figure 2 shows that this homemade setup 
provides observation of both sides of the drum (advancing and receding contact angles) when half immersed in two immiscible liquids. The influence of surfactant in the organic phase was characterized for different rotation speeds and different surfactant concentrations.

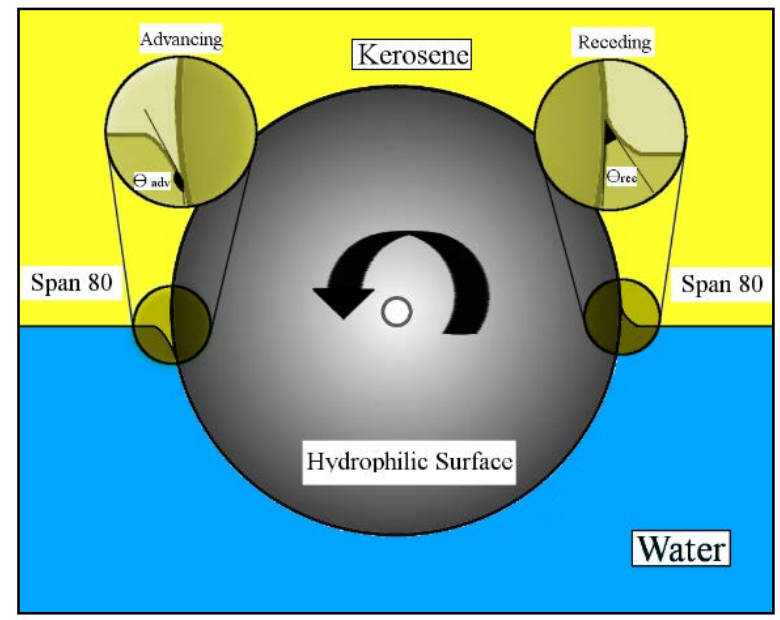

Figure 2 Schematic diagram of a side view of a drum half immersed in aqueous phase and half immersed in an organic phase sometimes with surfactant $\left(\operatorname{Span}^{\circledR} 80\right)$.

Several authors observed that contact angle depends on both surface properties and on the surfactant used [19, 25, 26]. Different concentrations of the same surfactant influence on the contact angle, using an identical surface to membrane emulsification tests, was investigated. 


\section{Material and methods}

In the emulsification experiments, a solution of $13.5 \%(\mathrm{w} / \mathrm{w})$ Poly(vinyl alcohol (PVA, $\mathrm{M}_{\mathrm{w}}$ 13000 - 23000 87-89\% hydrolysed Sigma Aldrich, UK) was used as the disperse phase, while the continuous phase was kerosene (reagent grade, low odour, Sigma Aldrich, UK) containing an (oil soluble) surfactant - Span $80^{\circledR}$ (Sigma Aldrich, UK), which was used at various concentrations between 5-100 mM. The membrane emulsification device used was a Dispersion Cell (see Figure 3) supplied by Micropore Technologies Ltd. This device uses a 24 Volt DC motor to drive a paddle stirrer, which provides shear at the membrane surface (Figure 3a and 3b). A paddle stirring speed of 800 RPM (8 Volts) was used for all the experiments providing a maximum shear at the membrane surface of $5.8 \mathrm{~Pa}$. The method used to determine the maximum shear is described in [5] using a density value of $780 \mathrm{~kg} / \mathrm{m} 3$ and a viscosity of $1.64 \times 10^{-3} \mathrm{~Pa}$ s). A syringe pump (World Precision Instruments, Florida, USA) was used to provide pulseless flow. Two different injection rates were tested: 0.2 and $0.5 \mathrm{~mL} / \mathrm{min}$. The continuous phase volume was $100 \mathrm{~mL}$, and $5 \mathrm{~mL}$ of disperse phase was injected though the membrane for each experiment. A flat disc membrane containing uniform cylindrical pores of $10 \mu \mathrm{m}$ pore size and pore spacing of $200 \mu \mathrm{m}$ was provided by Micropore Technologies, Ltd. The membrane surface was not treated, it was bare 316 stainless steel. The membrane used had an annular ring of open pores as presented in Figure 3c. Regarding the experimental equipment used: $\mathrm{H}=110 \mathrm{~mm}, \mathrm{D}=30.0 \mathrm{~mm}, \mathrm{~b}=11.8 \mathrm{~mm}$ and $\mathrm{T}=34.3 \mathrm{~mm}$.

Before each experiment, the membrane was cleaned. The standard cleaning consisted of soaking the membrane in $4 \mathrm{M} \mathrm{NaOH}$ solution for 10 minutes, followed by rinsing with tap water and then placing in distilled water for 1 minute. Afterwards, the membrane was soaked in $2 \%$ wt. citric acid solution for 10 minutes, rinsed with tap water and again placed in distilled water for 1 minute. Finally, the membrane was dried and stored, or pre-soaked in the 
continuous phase, getting ready for the next experiment. Every time that the membrane solution was changed, an ultrasonic bath was used for 1 minute to promote the cleaning and/or remove any air bubbles that may be present in the membrane pores. After cleaning, the membrane was immersed into the continuous phase for about 30 minutes after being ultrasonicated for about 1 minute. This is important to ensure that the membrane was wetted by the continuous phase and no air was trapped in the pores. Then, the membrane was placed into the base of the Dispersion Cell, and, after assembly of this device, about $100 \mathrm{~mL}$ of continuous phase was placed inside the glass cylinder. To ensure that no air was present, continuous phase was pulled through the membrane using a three-way valve and syringes. Finally, a syringe was loaded with disperse phase, placed in the syringe pump and connected to the three-way valve. The three-way valve was turned and the injection started, monitoring to check that no air bubbles were present between the interface of disperse phase/continuous phase.

a)



b)

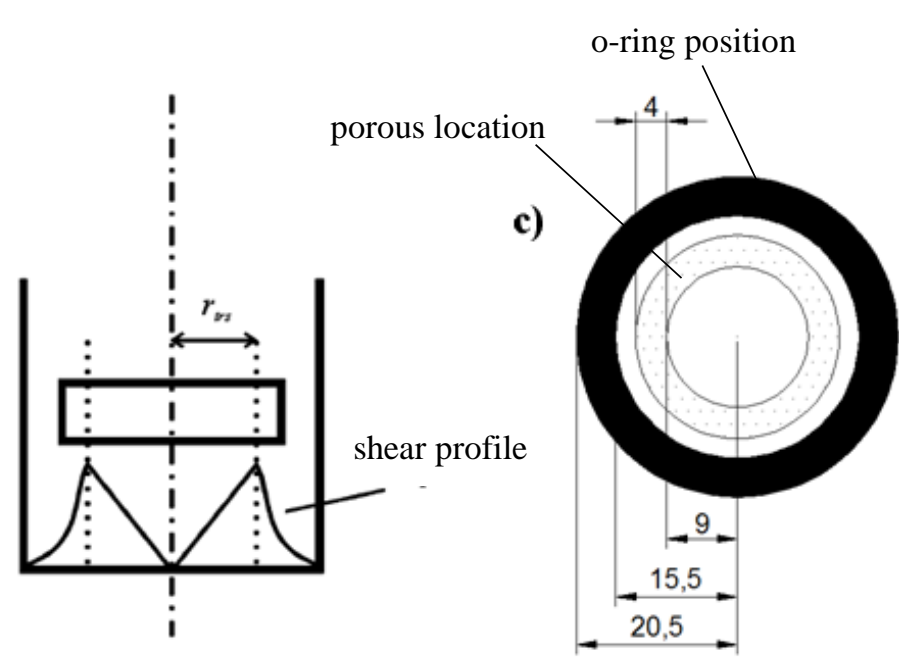

Figure 3 Schematic diagrams showing (a) the stirred cell, (b) the shear profile under the stirrer, and (c) the annular radial ring membrane for dispersion. Adapted from [5]. 


\subsection{Measurements of mean droplet size and droplet size distribution}

The droplet diameter is expressed as the volume median diameter $\mathrm{D}(\mathrm{V}, 0.5)$, which is the diameter corresponding to $50 \%$ on the cumulative volume distribution curve. The droplet size uniformity is expressed in terms of coefficient of variation (CV)

$$
C V=\frac{\sigma}{\mu} \times 100
$$

where $\sigma$ is the standard deviation and $\mu$ is the mean of the volume distribution curve. The CV and $\mathrm{D}(\mathrm{V}, 0.5)$ reported were obtained by static image analysis where a large number of (typically over a thousand) drops were counted and measured using the microscope and Image $\mathrm{J}$ (image processing software) in a process automated by running a MATLAB ${ }^{\circledR}$ script.

\subsection{Static contact angles}

Sessile drops experiments were carried out to determine the static contact angle of water drops on non-treated 316 stainless steel (SS) sheets $(0.1$ x 25 x $25 \mathrm{~mm})$ purchased from GoodFellow Ltd, immersed in kerosene which contained different amounts of $\operatorname{Span}^{\circledR} 80$ dissolved (0-100 mM). These SS sheets and membranes were handled similarly in order to achieve comparable/transferable results between different measurements. Solutions used in the sessile drop experiments were: for the droplet phase, distilled water, $10 \%$ (w/w) $\mathrm{NaCl}$ and 13.5\% (w/w) PVA solution while the surrounding (i.e. continuous) phase was kerosene with various amounts of $\operatorname{Span}^{\circledR}$ 80. Snapshots were taken every $0.5 \mathrm{~s}$ as soon as a drop was generated and its shape was fitted according to the Young-Laplace equation using a drop shape analyser (DSA-100, Krüss, Germany) to determine the contact angle. Final contact angle corresponds to measurements when the drop shape became stable. These measurements were made (at least) in triplicate and the mentioned values are averages. 


\subsection{Dynamic contact angles (rotating drum system)}

A home built rotating drum system (Figure 4) was used for measurements of the dynamic advancing and receding contact angles. In these experiments, one planar exchangeable drum was used, made of stainless steel with the following dimensions: $6 \mathrm{~cm}$ diameter and $2 \mathrm{~cm}$ width (Figure 4b).

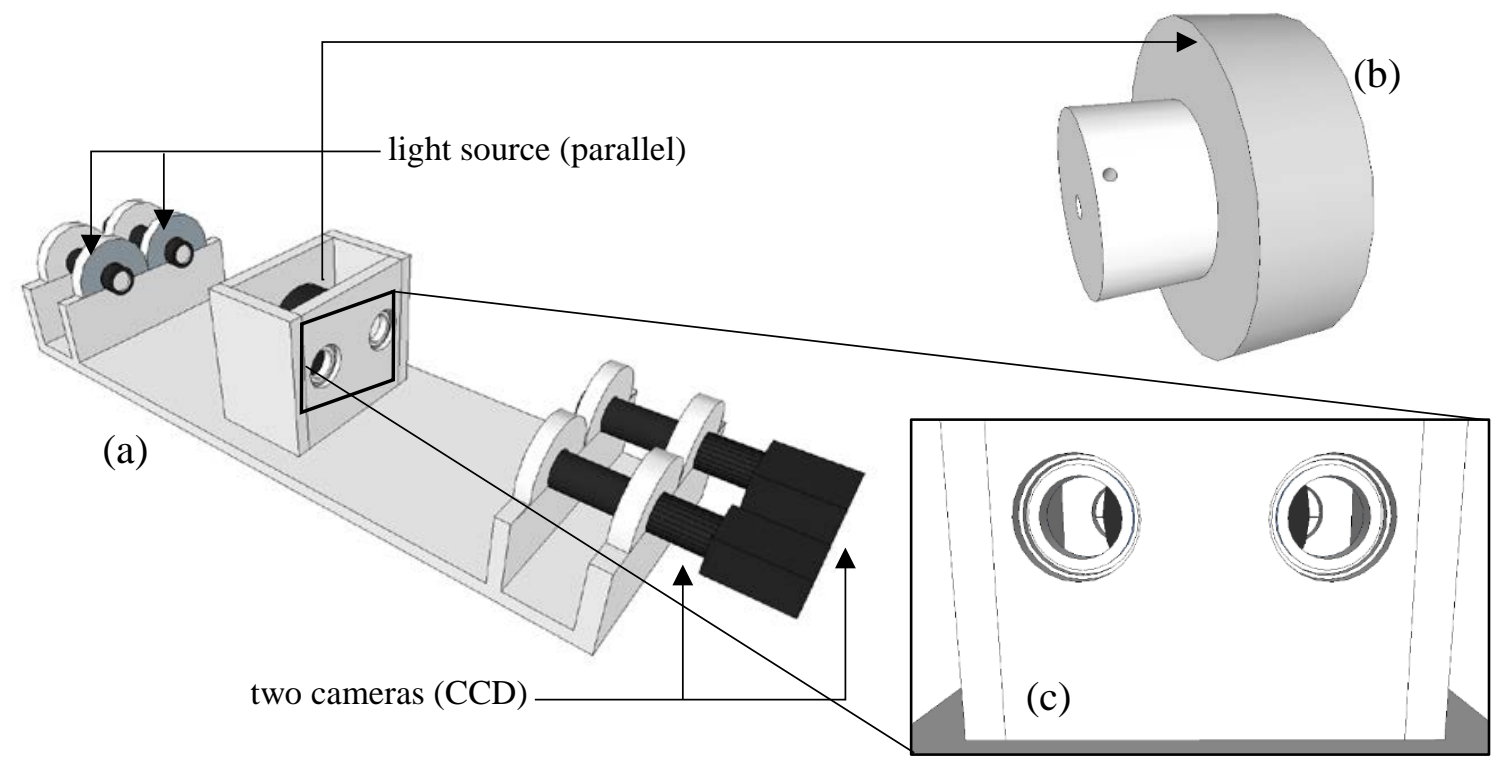

Figure 4 Rotating drum system (a) setup 3D view; (b) stainless steel drum; (c) cameras view.

The DC motor rotated the drum with peripheral speeds of between $1 \mathrm{~mm} \mathrm{~s}^{-1}$ and $10 \mathrm{~mm} \mathrm{~s}^{-1}$. The maximum velocity depends on the capillary number of the system which shouldn't be higher than $10^{-4}$ in order to avoid the dominance of viscous forces over the capillary forces. Two cameras were mounted on each side of the drum to capture the side view. One of them was an ImagingSource DMK 23G445 and the other one was a Baumer EXG50. Both cameras had Bi-telecentric objective lenses TC23009 from Opto Engineering, with a magnification of 1.000x. Two blue Telecentric HP illuminators from Opto Engineering were used as light sources. 
Dynamic and receding contact angles were observed simultaneously, via side-view, at low frame rate $\left(<10 \mathrm{fp} \mathrm{s}^{-1}\right)$. Cameras were mounted on a movable (horizontally) frame to focus on the three-phase contact line. The light source was mounted on the same frame at the opposite window, to achieve a black and white image. Light source and camera were mounted in the same frame to ensure that they were parallel to each other, which is important for higher accuracy of contact angle measurements. Therefore, other light present in the laboratory would not interfere with the experimental measurements.

\subsection{Interfacial tension measurements}

Dynamic interfacial tension was measured with a DSA-100, (Krüss, Germany) using bubble shape analysis by the pendant drop method. These experiments were performed at room temperature $\left(22 \pm 2{ }^{\circ} \mathrm{C}\right)$. The same solutions that were used in the static contact angle measurements were used in the interfacial tension measurements: for the droplet phase, distilled water, $10 \%(\mathrm{w} / \mathrm{w}) \mathrm{NaCl}$ and $13.5 \%(\mathrm{w} / \mathrm{w})$ PVA solution were used while the surrounding (i.e. continuous) phase was kerosene with various amounts of $\operatorname{Span}^{\circledR} 80$. The experiment was deemed to have finished when the interfacial tension measurements achieved an equilibrium value. These measurements were performed in triplicate. 


\section{Results and Discussion}

\subsection{Sessile droplets experiments}

Initially spreading of aqueous drops on the metal surface without presence of either surfactant or the immiscible liquid, i.e., just vapour phase surrounding the metal sheet, was investigated; and later in the presence of surrounding liquid phase: kerosene with, or without, surfactant. Table 1 summarises the apparent static contact angle obtained for these experiments.

Table 1 Static contact angles obtained from sessile drop experiments

\begin{tabular}{c|c|c}
\hline Drop phase & Surrounding phase & $\Theta\left({ }^{\circ}\right)$ \\
\hline \multirow{2}{*}{ (Pure) water } & Vapour & $45.9 \pm 9.8$ \\
\cline { 2 - 3 } & Kerosene & $55.3 \pm 8.9$ \\
\hline \multirow{2}{*}{$10 \% \mathrm{NaCl}$} & Vapour & $52.2 \pm 5.2$ \\
\cline { 2 - 3 } & Kerosene & $69.2 \pm 9.3$ \\
\hline \multirow{2}{*}{$13.5 \% \mathrm{PVA}$} & Vapour & $37.4 \pm 3.9$ \\
\cline { 2 - 3 } & Kerosene & $43.7 \pm 3.9$ \\
\hline
\end{tabular}

Table 1 shows that when the surrounding phase was just vapour, the stainless steel is partially wetted by the three-different water based drops tested $\left(\Theta<90^{\circ}\right)$, that is it shows hydrophilic behaviour. When kerosene is present, the contact angle increased, however, all drops tested showed partial wetting behaviour. The observed increase of contact angle can be explained by the decrease of the interfacial tension between liquid-liquid compared to the surface tension (liquid-vapour) as is predicted by Young equation:

$$
\gamma_{s v}=\gamma_{s l}+\gamma_{l v} \cos \theta
$$

where $\gamma_{\mathrm{sv}}$ is the solid-vapour (or immiscible liquid) energy, $\gamma_{\mathrm{sl}}$ is the solid liquid interfacial energy, $\gamma_{\mathrm{lv}}$ is the liquid vapour (or immiscible liquid) interfacial energy, i.e., surface (or interfacial) tension and $\Theta$ is the resultant contact angle (see Figure 5): 


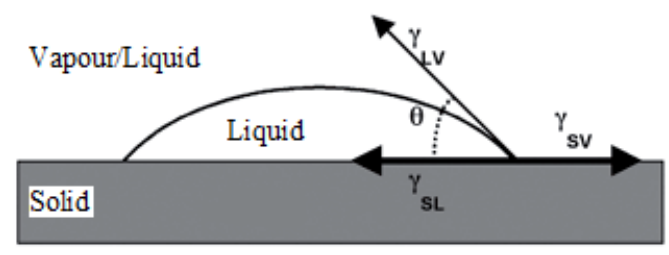

Figure 5 Liquid drop on a solid surface showing the interfacial tensions at the three-phase contact line.

Figure 6 shows that the apparent contact angle increased, with the presence of higher amounts of the surfactant $\operatorname{Span}^{\circledR} 80$, reaching a constant value when surfactant concentrations used were slightly above the critical micelle concentration $(0.5 \mathrm{mM}$, see Figure 8$)$. In experiments when the concentrations above CMC were used, a lag time was observed before spreading starts. This lag time increased with higher surfactant concentration and it could take several seconds, or even minutes, before spreading starts. However, this lag time was difficult to determine because it varied between experiments using identical conditions. Once the spreading starts, the resultant contact angle is nearly constant and experiments were very reproducible (see Figure 6). The lowest contact angles were obtained using PVA, followed by pure water then saline water. As expected, the presence of PVA decreased the contact angle, as was previously observed, as this polymer is surface active (lowering the interfacial tension). On the other hand, using saline water contact angles observed were overall higher compared to pure water. These results cannot be explained by change of the interfacial tension, since interfacial tension measured, practically, didn't change in the presence of salt in the drop (see Figure 7). 




Figure 6 Contact angles of three different drop phases (• pure water; $\circ$ saline water $(10 \%$ $(\mathrm{w} / \mathrm{w}) \mathrm{NaCl}$ ) and $\Delta 13.5 \%(\mathrm{w} / \mathrm{w})$ PVA in water) surrounded by different surfactant concentrations present in kerosene on a non-treated (hydrophilic stainless steel sheet.

Contact angle measurements with $13.5 \%$ of PVA $\left(90^{\circ}<\Theta<110^{\circ}\right)$ show that droplets formed during emulsification experiments should not wet the membrane surface at concentrations of $\operatorname{Span}^{\circledR} 80$ above CMC (between 10 and $100 \mathrm{mM}$ ) (see Figure 6). Another important observation is the presence of the lag time: which means that in the course of membrane emulsification (which occurs faster than the lag time) the forming droplet at the membrane pore surface does not have enough time to spread over the membrane surface. However, wetting may occur because the generation of drops in membrane emulsification is a very dynamic process: after the drop forms and detaches from the membrane surface surfactant must diffuse from the bulk to the membrane surface. The latter process may result in a partial wetting of the membrane surface. 




- Drop phase: water $\quad$ oDrop phase: $10 \%$ wt NaCl $\quad \Delta$ Drop phase: $13.5 \%$ wt PVA

Figure 7 Interfacial tension between drop phases: • pure water; o saline water $(10 \%(\mathrm{w} / \mathrm{w})$ $\mathrm{NaCl})$ and $\Delta$ 13.5\%(w/w) PVA in water) and surrounding phase that contained different surfactant concentrations present in kerosene using pendant drop technique.

\subsection{Dynamic contact angles}

A rotating drum setup was used to characterize wetting and dewetting of the surface when in contact with two immiscible liquids. Data plotted in Figure 8 were obtained monitoring the interface from both sides of the rotating drum between an aqueous phase and kerosene with and without presence of surfactant. Therefore, advancing and receding contact angles were determined for different speeds $(0-8 \mathrm{~mm} / \mathrm{s})$. These are relatively low speeds compared to the studies undertaken by G. K. Auernhammer and his colleagues [21-24], where dynamic receding contact angle measurements showed a decrease with increasing velocity as well as with increasing surfactant concentrations. It was postulated in [19-22] that Marangoni stresses were the main contribution to the contact angle shift. These stresses occur due to local surface tension gradients formed close to the three-phase contact line. It was shown that hydrodynamic models [27-29] fit the experiment data for velocities above $10 \mathrm{~mm} / \mathrm{s}$ despite the presence of Marangoni flow near to the contact line. 
However, none of the mentioned above hydrodynamic models could explain the experimental data obtained in this study using two liquids. Nevertheless, this is in agreement with their observations because in this study only velocities below $10 \mathrm{~mm} / \mathrm{s}$ were tested. A suitable model should be developed to predict the behaviour for low velocities and applicable for a two-liquid system. Figure 8 shows that dynamic receding contact angle decreases with increase of velocity as well as with increase of surfactant concentrations.



Figure 8 Dynamic advancing and receding contact angles against rotation speed for different surfactant concentrations (three phase contact: hydrophilic drum, kerosene in the presence of $\operatorname{Span}^{\circledR} 80$ and water).

The advancing contact angles increased with velocity as well as surfactant concentration increase. It was also observed that a film of the organic phase formed (phase that contained surfactant) for concentrations above $12.5 \%$ CMC of $\operatorname{Span}^{\circledR}$ 80. After the film was formed the advancing contact angle reached a steady state and the liquid no longer de-wet from the surface. The presence of the film was clearly seen due to the shift of the contact angle (see Figure 9). Therefore, these observations support the fact that this substrate will preferably wet 
by the phase that contains surfactant, even at very low concentrations (12.5\% CMC) well below to the surfactant concentrations used in membrane emulsification processes.



Figure 9 Pictures of advancing (left column) and receding contact angle (right column) before and after film formation for concentrations above 12.5\% CMC in the organic phase.

Measurements of the reported dynamic contact angles provide valuable information which can be applied to membrane emulsification, or other processes using two liquid systems in which surfactants are present. To give a practical example, many membranes used in membrane emulsification have a natural hydrophilic behaviour and conventionally, these membranes need to receive a hydrophobic treatment when the aim is to produce w/o emulsions. However, the experiments reported above show that an organic phase can wet a hydrophilic surface completely, using very low surfactant concentrations, without dewetting in presence of an aqueous phase. So, these are encouraging results in the case when the aim is to produce w/o emulsions using a hydrophilic membrane. 


\subsection{Droplet formation experiments}

Droplet size and droplet size distribution after emulsification using the Dispersion Cell for various concentrations of surfactant are presented in Figure 10, which shows that a wide range of droplet sizes can be obtained just by varying the surfactant concentration and using the same conditions, i.e., pore size, shear or injection rate. This demonstrates the importance of interfacial science in processes such as membrane emulsification. Not only surfactant concentration, but also type of surfactant plays a key role where surface activity would define the rate of surfactant adsorption to liquid interface, or liquid/solid interface. In addition, this has been acknowledged in different studies [30-32] enhancing the need for knowledge of surfactant proprieties which would facilitate the process design and optimisation at production scale.

It is also seen in Figure 10 that for the two flow rates tested, higher surfactant concentration results in decrease of the resultant drop size. This can be explained by dynamic interfacial tension, i.e., higher surfactant concentration increases the rate of adsorption to the fresh interface generated by drop formation and therefore reduction of interfacial tension is faster, and consequently, a smaller time for drop growth and detachment, producing smaller drops.

Figure 10 shows that a lower injection rate results in a narrower drop size distribution. These results fit very well with the observations and results obtained in the previous sections, where it was shown that surfactant present tends to adsorb to the solid surface facilitating its wetting. Narrower drop size distributions obtained with lower injection rate can be due to: expansion rate of the droplets is lower, allowing more time for the surfactant to adsorb to the drop and surface which could possibly contribute to avoid wetting and consequently more uniform drop size generation. A picture of some droplets formed at $0.2 \mathrm{~mL} \mathrm{~min}{ }^{-1}$ (corresponding to a superficial velocity of $43.4 \mathrm{~L} \mathrm{~m}^{-2} \mathrm{~h}^{-1}$ ) is shown in Figure 11 with the size distribution. 


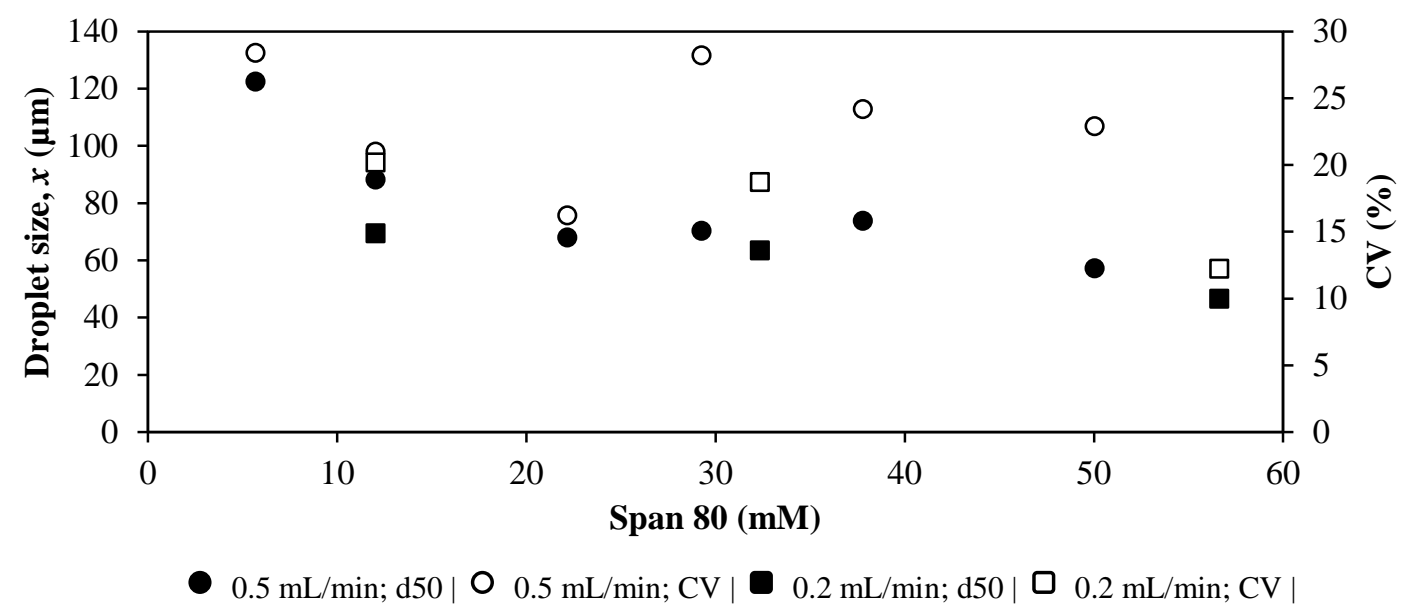

Figure 10 Influence of two different injection rate used on the droplet size (d50) and on droplet size distribution (CV) as a function of surfactant concentration.

The CV values obtained using a hydrophilic membrane to produce w/o emulsions are comparable to other studies where membrane emulsification process was adopted, but a hydrophobic membrane was utilised [4, 33-35]. Emulsion manufacturing using the Dispersion Cell is a batch process which means that during droplet formation surfactant will be depleted from the organic media. To prevent this being a major disadvantage the ratio between disperse and continuous phases should be kept low (5\% v/v).


Figure 11 Droplets formed during injection of $13.5 \%$ PVA solution at $0.2 \mathrm{~mL} \mathrm{~min}^{-1}$ in to kerosene with $50 \mathrm{mM} \mathrm{Span}{ }^{\circledR} 80$ concentration using a surface shear of $5.8 \mathrm{~Pa}$ and a (nontreated) hydrophilic membrane, i.e., relying on the surfactant present in the organic phase to wet membrane and avoid its dewetting by the (aqueous) disperse phase. 


\section{Conclusions}

It is possible to produce uniform w/o emulsions using a hydrophilic membrane for membrane emulsification. Therefore, no membrane surface treatment may be required contrary to conventionally accepted wisdom, where when producing water droplets a hydrophobic membrane is usually specified. This result is possible using an appropriate surfactant in the continuous phase. The presence of surfactants assists in the better wetting of the membrane by the organic phase and in doing this preventing the dispersed phase (water) from wetting the membrane surface. Static and dynamic contact angle measurements were performed to show that stainless steel is wetted by the organic phase, when surfactant is present in the organic phase, rather than in the aqueous phase. It is shown that, an untreated (hydrophilic) stainless steel porous membrane is shown to be effective in the production of uniform PVA droplets, when generating a w/o emulsion. This is relevant for applications where a uniform and controlled production of w/o emulsions by membrane emulsification is required and when a hydrophobic membrane surface treatment/coating is not recommended, due to the chemicals used, or due to the poor stability of this treatment/coating over a long-time exposure to the liquids used in the formulation chosen.

\section{Acknowledgements}

P. Silva kindly acknowledges Dr. Sergey Zhdanov for his help with designing and manufacturing the rotating drum setup. P. Silva also kindly acknowledges Dr. Günter K. Auernhammer and Dorota Linke for the scientific discussions and their insight regarding the rotating drum experiments. This work was supported by Micropore Technologies Ltd and funded by a Marie Curie Intra-European Fellowship within the $7^{\text {th }}$ European Community Framework Programme. 


\section{List of Figures:}

Figure 1 Influence of the contact angle on the final drop size..............................................

Figure 2 Schematic diagram of a side view of a drum half immersed in aqueous phase and half immersed in an organic phase sometimes with surfactant $\left(\operatorname{Span}^{\circledR} 80\right)$...........................6 Figure 3 Schematic diagrams showing (a) the stirred cell, (b) the shear profile under the stirrer, and (c) the annular radial ring membrane for dispersion. Adapted from [5]. . .8 Figure 4 Rotating drum system (a) setup 3D view; (b) stainless steel drum; (c) cameras view.

Figure 5 Liquid drop on a solid surface showing the interfacial tensions at the three-phase contact line.

Figure 6 Contact angles of three different drop phases (• pure water; $\circ$ saline water $(10 \%$ $(\mathrm{w} / \mathrm{w}) \mathrm{NaCl}$ ) and $\Delta 13.5 \%(\mathrm{w} / \mathrm{w})$ PVA in water) surrounded by different surfactant concentrations present in kerosene on a non-treated (hydrophilic stainless steel sheet. .14 Figure 7 Interfacial tension between drop phases: • pure water; o saline water $(10 \%(\mathrm{w} / \mathrm{w})$ $\mathrm{NaCl})$ and $\Delta$ 13.5\%(w/w) PVA in water) and surrounding phase that contained different surfactant concentrations present in kerosene using pendant drop technique. .15

Figure 8 Dynamic advancing and receding contact angles against rotation speed for different surfactant concentrations (three phase contact: hydrophilic drum, kerosene in the presence of Span ${ }^{\circledR} 80$ and water). 16

Figure 9 Pictures of advancing (left column) and receding contact angle (right column) before and after film formation for concentrations above 12.5\% CMC in the organic phase. Figure 10 Influence of two different injection rate used on the droplet size (d50) and on droplet size distribution (CV) as a function of surfactant concentration. .19

Figure 11 Droplets formed during injection of $13.5 \%$ PVA solution at $0.2 \mathrm{~mL} \mathrm{~min}^{-1}$ in to kerosene with $50 \mathrm{mM} \operatorname{Span}^{\circledR} 80$ concentration using a surface shear of $5.8 \mathrm{~Pa}$ and a (nontreated) hydrophilic membrane, i.e., relying on the surfactant present in the organic phase to wet membrane and avoid its dewetting by the (aqueous) disperse phase. .19 


\section{List of Tables:}

Table 1 Static contact angles obtained from sessile drop experiments...................................12 


\section{References}

1. Silva, P.S., M.M. Dragosavac, G.T. Vladisavljević, H.C.H. Bandulasena, R.G. Holdich, M. Stillwell, and B. Williams, Azimuthally oscillating membrane emulsification for controlled droplet production. AIChE Journal, 2015. 61(11): p. 3607-3615.

2. Schroën, K., M. Ferrando, S. de Lamo-Castellví, S. Sahin, and C. Güell, Linking Findings in Microfluidics to Membrane Emulsification Process Design: The Importance of Wettability and Component Interactions with Interfaces. Membranes, 2016. 6(2): p. 26.

3. Imbrogno, A., M.M. Dragosavac, E. Piacentini, G.T. Vladisavljević, R.G. Holdich, and L. Giorno, Polycaprolactone multicore-matrix particle for the simultaneous encapsulation of hydrophilic and hydrophobic compounds produced by membrane emulsification and solvent diffusion processes. Colloids and Surfaces B: Biointerfaces, 2015. 135: p. 116-125.

4. Morelli, S., R.G. Holdich, and M.M. Dragosavac, Chitosan and Poly (Vinyl Alcohol) microparticles produced by membrane emulsification for encapsulation and $\mathrm{pH}$ controlled release. Chemical Engineering Journal, 2016. 288: p. 451-460.

5. Stillwell, M.T., R.G. Holdich, S.R. Kosvintsev, G. Gasparini, and I.W. Cumming, Stirred cell membrane emulsification and factors influencing dispersion drop size and uniformity. Industrial \& Engineering Chemistry Research, 2007. 46(3): p. 965-972.

6. Gasparini, G., S.R. Kosvintsev, M.T. Stillwell, and R.G. Holdich, Preparation and characterization of PLGA particles for subcutaneous controlled drug release by membrane emulsification. Colloids and Surfaces B: Biointerfaces, 2008. 61(2): p. 199-207. 
7. Dragosavac, M.M., G.T. Vladisavljević, R.G. Holdich, and M.T. Stillwell, Production of Porous Silica Microparticles by Membrane Emulsification. Langmuir, 2012. 28(1): p. 134-143.

8. Kosvintsev, S.R., G. Gasparini, R.G. Holdich, I.W. Cumming, and M.T. Stillwell, Liquid-liquid membrane dispersion in a stirred cell with and without controlled shear. Industrial \& Engineering Chemistry Research, 2005. 44(24): p. 9323-9330.

9. Nakashima, T., M. Shimizu, and M. Kukizaki, Membrane emulsification by microporous glass. Inorganic Membranes : Icim2-91, ed. A.J. Burggraaff, J. Charpin, and L. Cot1991. 513-516.

10. Omi, S., Preparation of monodisperse microspheres using the Shirasu porous glass emulsification technique. Colloids and Surfaces A: Physicochemical and Engineering Aspects, 1996. 109: p. 97-107.

11. Joscelyne, S.M. and G. Trägårdh, Food emulsions using membrane emulsification: conditions for producing small droplets. Journal of Food Engineering, 1999. 39(1): p. 59-64.

12. Peng, S.J. and R.A. Williams, Controlled production of emulsions using a crossflow membrane part I: Droplet formation from a single pore. Chemical Engineering Research \& Design, 1998. 76(A8): p. 894-901.

13. Schroder, V., O. Behrend, and H. Schubert, Effect of dynamic interfacial tension on the emulsification process using microporous, ceramic membranes. Journal of Colloid and Interface Science, 1998. 202(2): p. 334-340.

14. Holdich, R.G., M.M. Dragosavac, G.T. Vladisavljevic, and S.R. Kosvintsev, Membrane Emulsification with Oscillating and Stationary Membranes. Industrial \& Engineering Chemistry Research, 2010. 49(8): p. 3810-3817. 
15. Dragosavac, M.M., R.G. Holdich, G.T. Vladisavljević, and M.N. Sovilj, Stirred cell membrane emulsification for multiple emulsions containing unrefined pumpkin seed oil with uniform droplet size. Journal of Membrane Science, 2012. 392-393: p. 122129.

16. Egidi, E., G. Gasparini, R.G. Holdich, G.T. Vladisavljevic, and S.R. Kosvintsev, Membrane emulsification using membranes of regular pore spacing: Droplet size and uniformity in the presence of surface shear. Journal of Membrane Science, 2008. 323(2): p. 414-420.

17. Holzapfel, S., E. Rondeau, P. Muhlich, and E.J. Windhab, Drop Detachment from a Micro-Engineered Membrane Surface in a Dynamic Membrane Emulsification Process. Chemical Engineering \& Technology, 2013. 36(10): p. 1785-1794.

18. Maan, A.A., K. Schroën, and R. Boom, Monodispersed water-in-oil emulsions prepared with semi-metal microfluidic EDGE systems. Microfluidics and Nanofluidics, 2013. 14(1): p. 187-196.

19. Maan, A.A., S. Sahin, L.H. Mujawar, R. Boom, and K. Schroën, Effect of surface wettability on microfluidic EDGE emulsification. Journal of Colloid and Interface Science, 2013. 403: p. 157-159.

20. Keurentjes, J.T.F., M.A.C. Stuart, D. Brinkman, C.G.P.H. Schroën, and K. van 't Riet, Surfactant-induced wetting transitions: Role of surface hydrophobicity and effect on oil permeability of ultrafiltration membranes. Colloids and Surfaces, 1990. 51: p. 189-205.

21. Truszkowska, D., F. Henrich, J. Schultze, K. Koynov, H.J. Räder, H.J. Butt, and G.K. Auernhammer, Forced dewetting dynamics of high molecular weight surfactant solutions. Colloids and Surfaces A: Physicochemical and Engineering Aspects, 2016. 
22. Fell, D., N. Pawanrat, E. Bonaccurso, H.-J. Butt, and G.K. Auernhammer, Influence of surfactant transport suppression on dynamic contact angle hysteresis. Colloid and Polymer Science, 2013. 291(2): p. 361-366.

23. Fell, D., G. Auernhammer, E. Bonaccurso, C. Liu, R. Sokuler, and H.-J. Butt, Influence of Surfactant Concentration and Background Salt on Forced Dynamic Wetting and Dewetting. Langmuir, 2011. 27(6): p. 2112-2117.

24. Henrich, F., D. Fell, D. Truszkowska, M. Weirich, M. Anyfantakis, T.-H. Nguyen, M. Wagner, G.K. Auernhammer, and H.-J. Butt, Influence of surfactants in forced dynamic dewetting. Soft Matter, 2016. 12(37): p. 7782-7791.

25. Kawakatsu, T., G. Trägårdh, C. Trägårdh, M. Nakajima, N. Oda, and T. Yonemoto, The effect of the hydrophobicity of microchannels and components in water and oil phases on droplet formation in microchannel water-in-oil emulsification. Colloids and Surfaces A: Physicochemical and Engineering Aspects, 2001. 179(1): p. 29-37.

26. Saito, M., L.-J. Yin, I. Kobayashi, and M. Nakajima, Preparation characteristics of monodispersed oil-in-water emulsions with large particles stabilized by proteins in straight-through microchannel emulsification. Food Hydrocolloids, 2005. 19(4): p. 745-751.

27. Voinov, O.V., Hydrodynamics of wetting. Fluid Dynamics, 1976. 11(5): p. 714-721.

28. Cox, R.G., The dynamics of the spreading of liquids on a solid surface. 1. Viscous flow. Journal of Fluid Mechanics, 1986. 168: p. 169-194.

29. Cox, R.G., The dynamics of the spreading of liquids on a solid surface. 2. Surfactants Journal of Fluid Mechanics, 1986. 168: p. 195-220.

30. van der Graaf, S., C.G.P.H. Schroën, R.G.M. van der Sman, and R.M. Boom, Influence of dynamic interfacial tension on droplet formation during membrane emulsification. Journal of Colloid and Interface Science, 2004. 277(2): p. 456-463. 
31. Rayner, M., G. Trägårdh, and C. Trägårdh, The impact of mass transfer and interfacial expansion rate on droplet size in membrane emulsification processes. Colloids and Surfaces A: Physicochemical and Engineering Aspects, 2005. 266(1-3): p. 1-17.

32. Kobayashi, I., M. Yasuno, S. Iwamoto, A. Shono, K. Satoh, and M. Nakajima, Microscopic observation of emulsion droplet formation from a polycarbonate membrane. Colloids and Surfaces A: Physicochemical and Engineering Aspects, 2002. 207(1-3): p. 185-196.

33. Yamazaki, N., K. Naganuma, M. Nagai, G.H. Ma, and S. Omi, Preparation of W/O (Water-in-Oil) Emulsions Using a PTFE (Polytetrafluoroethylene) Membrane-A New Emulsification Device. Journal of Dispersion Science and Technology, 2003. 24(2): p. 249-257.

34. Mi, Y., W. Zhou, Q. Li, F. Gong, R. Zhang, G. Ma, and Z. Su, Preparation of waterin-oil emulsions using a hydrophobic polymer membrane with 3D bicontinuous skeleton structure. Journal of Membrane Science, 2015. 490: p. 113-119.

35. Cheng, C.-J., L.-Y. Chu, and R. Xie, Preparation of highly monodisperse W/O emulsions with hydrophobically modified SPG membranes. Journal of Colloid and Interface Science, 2006. 300(1): p. 375-382. 